\title{
Effect of stocking density on behavioral traits, blood biochemical parameters and immune responses in meat ducks exposed to heat stress
}

\author{
Byung-Sung Park ${ }^{1}$, Kyung-Hwan Um ${ }^{1}$, Sang-O Park ${ }^{1}$, and Victor A. Zammit ${ }^{2}$ \\ ${ }^{1}$ College of Animal Life Science, Kangwon National University, Chuncheon, \\ Gangwondo, 200-701, South Korea \\ ${ }^{2}$ Metabolic Biochemistry, Warwick Medical School, University of Warwick, \\ Coventry CV4 7AL, UK \\ Correspondence: Sang-O Park (sopark@kangwon.ac.kr)
}

Received: 14 July 2018 - Revised: 9 October 2018 - Accepted: 15 October 2018 - Published: 30 October 2018

\begin{abstract}
High stocking density (HSD) and heat stress (HS) caused by climate change can lower blood homeostasis and negatively impact the behavioral traits of animals. The objective of this study was to explore the influence of stocking densities on behavioral traits, blood parameters, immune responses, and stress hormones in meat ducks (Cherry valley, Anas platyrhynchos) exposed to HS. A total of 320 meat ducks were assigned to four groups with different stocking densities using a randomized complete block design. The ducks were then reared for 42 days. The assigned density groups were as follows: (1) control group (CON, three birds $\mathrm{m}^{-2}$, normal environmental heat conditions); (2) low stocking density (LSD, three birds $\mathrm{m}^{-2}$, heat stress conditions); (3) medium stocking density (MSD, four birds $\mathrm{m}^{-2}$, heat stress conditions); and (4) high stocking density (HSD, six birds $\mathrm{m}^{-2}$, heat stress conditions). To induce HS, the environment of the poultry house was set to a temperature of $34 \pm 2{ }^{\circ} \mathrm{C}$ with a relative humidity of $70 \%$ from 11:00 to $16: 00$ for the finisher period (from day 22 to day 42 of the rearing period). Concentrations of blood triacylglycerol, total cholesterol, low-density lipoprotein cholesterol (LDL-C), aspartate aminotransferase (AST), and alanine aminotransferase (ALT) were higher in the HS groups compared with the CON group, with HSD showing the highest levels $(P<0.05)$. The concentrations of high-density lipoprotein cholesterol (HDL-C) and glucose were lower in the HSD groups than in the CON group $(P<0.05)$. Red blood cell (RBC) and platelet (PLT) counts were lower in HS groups compared with the CON group, with the HSD group displaying the lowest counts $(P<0.05)$. Blood $\mathrm{pH}$ values were also higher in the HS groups than in the CON group, with the highest values observed in the HSD group $(P<0.05)$. Concentrations of blood $p \mathrm{CO}_{2}, \mathrm{HCO}_{3}$, and $T \mathrm{CO}_{2}$ were higher in the $\mathrm{HS}$ groups than in the CON group, with HSD showing the lowest levels $(P<0.05)$. The concentration of $\mathrm{PO}_{2}$ was higher in $\mathrm{CON}$ than in any of the HS groups, with the lowest levels found in the HSD group $(P<0.05)$. The concentrations of blood $\operatorname{IgG}$ and corticosterone were increased in the HS groups compared with the CON group $(P<0.05)$. Animal behavioral trait scores were also higher in HS groups than in the CON group $(P<0.05)$; these scores were the highest in the HSD group. Overall, animal behavioral traits, blood biochemical parameters, and immune responses in meat ducks exposed to heat stress were highest in the HSD group, but not significantly different between the LSD or MSD groups.
\end{abstract}




\section{Introduction}

Heat stress (HS) and high stocking density (HSD) are known to negatively impact the behavioral traits and growth performance of animals while simultaneously increasing health problems and mortality (Daramola et al., 2012; Slimen, 2016). As birds, including ducks, are covered with feathers and do not have sweat glands, when they are exposed to high temperatures of around $41^{\circ} \mathrm{C}$ under HS and HSD conditions, their body temperatures continue to rise to levels that can damage homeostasis (Etches et al., 2008; Mello et al., 2015).

Another potential and pivotal issue regarding the rearing environment of poultry, particularly meat ducks, is the stocking density, which is known to affect animal behavioral traits. As the number of birds per space unit increases, economic gains can potentially be obtained. However, a high stocking density can be detrimental to animal growth performance, health, and behavioral traits and can lead to more serious damage (Xie et al., 2014). Therefore, increasing the stocking density as a way of boosting earnings has the potential to reduce productivity, especially when birds are exposed to HS during the summer (Chen et al., 2015). As the behavioral traits of animals can change as a result of changes in the rearing environment, the rearing field of economic animals has began to regulate the stocking density. The permissible stocking density for meat ducks in the USA is seven birds $\mathrm{m}^{-2}$ (HSUS, 2008). At stocking densities of more than nine birds $\mathrm{m}^{-2}$, the final body weights and the body weight gains of birds are decreased (Xie et al., 2014). In Korea, the optimal stocking density of meat ducks without any observable changes in the animal's behavioral traits is set at $10.2 \mathrm{~kg}$ (three birds) $\mathrm{m}^{-2}$.

HSD rearing can cause a number of problems, including damaging animal health as a result of negative impacts on behavioral traits. For birds under HS during the summer, the higher the stocking density, the lower their behavioral trait score with issues such as footpad dermatitis, scratches, bruising, and poorer feathering having been observed ( $\mathrm{Na}$ et al, 2012; Xie et al., 2014). Although there have been many studies focused on the effect of HS and stocking density on the productivity of broiler chickens (Yu et al., 2007; An et al., 2012), few such studies have been carried out on meat ducks. As HS in summer seasons can affect the nutritive condition and the activation of metabolism which affects homeostasis in birds, it is important to measure the blood biochemical parameters of the animals as biomarkers of their health (Aengwanich, 2007; Alaeldein, 2013; Habibu et al., 2014). These parameters have been used as general criteria for judging HS and the immunity of poultry (Habibu et al., 2014). In birds, including meat ducks, HS and HSD rearing can increase the excretion of potassium and sodium via fecal urine, which, in turn, can lower electrolytes and change the acid-base balance, the osmotic pressure, and the cell membrane potential (Bang et al., 2015). Poultry exposed to HS and HSD conditions are vulnerable to blood alkalosis caused by panting which can decrease blood gases such as $p \mathrm{CO}_{2}$ and increase blood pH (Borges et al., 2003, 2004). However, little is known about the effect of stocking density on factors such as the blood corticosterone level, the heterophil $(\mathrm{H})$ : lymphocyte $(\mathrm{L})$ ratio, and the duration of tonic immobility (TI duration) of meat ducks exposed to HS and HSD in the summertime (Altan et al., 2000; Turkyilmaz, 2008; Babacanoglu et al., 2013). Therefore, the objective of this study was to explore the influence of stocking density on behavioral traits, blood biochemical and hematological parameters, immunoglobulin $\mathrm{G}$, and corticosterone levels of meat ducks exposed to heat stress.

\section{Materials and methods}

\subsection{Animals and experimental design}

This study, which used laboratory animals, was approved by the Institutional Animal Care and Use Committee (IACUC) of Kangwon National University (approval no. 2013-0017). The experiment was conducted in accordance with regulations set forth in the European laboratory animal care licensing criteria (ScotPIL training manual, 1994). At the date of incubation, 320 male meat ducks were chosen and divided into grower periods (from day 1 to day 21) and finisher periods (from day 22 to day 42) for the purpose of rearing. HS was maintained in a poultry house where the environment was set to $34 \pm 2^{\circ} \mathrm{C}$ and a relative humidity of $70 \%$ from 11:00 to 16:00 for the finisher period (from day 22 to day 42). The birds were randomly divided into four groups: (1) the control group (CON, three birds $\mathrm{m}^{-2}$, normal environmental heat conditions); (2) low stocking density (LSD, three birds $\mathrm{m}^{-2}$, heat stress conditions); (3) medium stocking density (MSD, four birds $\mathrm{m}^{-2}$, heat stress conditions); and (4) high stocking density (HSD, six birds $\mathrm{m}^{-2}$, heat stress conditions). Each stocking density experiment was repeated on three different occasions. Commercial diets and experimental diets were divided and differentially fed to subject birds during grower periods (metabolizable energy, ME $2900 \mathrm{kcal} \mathrm{kg}^{-1}$, crude protein $22 \%$ ) and finisher periods (ME $3000 \mathrm{kcal} \mathrm{kg}^{-1}$, crude protein $18 \%$ ).

\subsection{Slaughter and blood sampling}

At the end of the experiment, 15 meat ducks per treatment group, which were representative of the average weight of the group, were chosen and blood samples were taken. Euthanasia was then stably administered via cervical dislocation; the animals were not stressed, in accordance with the recommendations for the euthanasia of laboratory animals (Close et al., 1997). Next, $5 \mathrm{~mL}$ of blood was collected from the wing vein of each meat duck and kept at room temperature for $15 \mathrm{~min}$ prior to centrifugation at $1008 \mathrm{~g}$ in order to obtain serum samples. To analyze blood biochemical parameters, serum sam- 
ples were rapidly frozen using $-196^{\circ} \mathrm{C}$ liquid nitrogen and then stored at $-20^{\circ} \mathrm{C}$ until the next measurement.

\subsection{Determination of biochemical parameters}

Triacylglycerol (TAG), total cholesterol (TC), low-density lipoprotein cholesterol (LDL-C), high-density lipoprotein cholesterol (HDL-C), glucose, alanine transferase (ALT), and aspartate aminotransferase (AST) levels were analyzed using a precision microplate reader (Molecular Devices Inc., New York, USA) following the protocol from the biochemical assay kit (Sigma-Aldrich, Co. Ltd., USA).

\subsection{Determination of hematological parameters}

Serum samples were thawed at $5^{\circ} \mathrm{C}$ and analyzed using an automated blood cell counter (VetScan I-STAT 1 handheld analyzer, Abaxis, USA) and a blood gas analyzer (RAPIDChem 744/754 blood gas analyzer, Simens, USA). Analyses were carried out within $1 \mathrm{~h}$ of sampling to determine the levels of hematocrit (HCT), red blood cells (RBC), mean corpuscular volume (MCV), mean corpuscular hemoglobin $(\mathrm{MCH})$, mean corpuscular hemoglobin concentration (MCHC), red blood cell distribution width (RDW), hemoglobin (HGB), platelet (PLT), plateletcrit (PCT), mean plasma volume (MPV), electrolytes, blood $\mathrm{pH}$, and blood gases of the birds to obtain their red blood cell and platelet profiles.

\subsection{Serum immunoglobulin $\mathrm{G}$ and corticosterone}

Levels of serum immunoglobulin $\mathrm{G}(\mathrm{IgG})$ and corticosterone were measured using a chicken ELISA kit (Bethyl Laboratories, Montgomery, TX, USA) and a corticosterone HS EIA kit (IDS, Ltd., Boldon, UK) in accordance with the protocols set by their manufacturers. The levels of these factors were calculated by measuring absorbances at $450 \mathrm{~nm}$ using a microplate reader (Molecular Devices Inc, New York, USA).

\subsection{Animal behavioral traits}

To determine the influence of HS on the daily behaviors of meat ducks, 24 meat ducks per treatment group were randomly selected and the behaviors of these birds were observed for $60 \mathrm{~min}$ each day under HS conditions (between 11:00 and 16:00). The control group was maintained under normal environmental heat conditions. Every movement of the chosen subject was monitored via video cameras (Camlife Image Recording Instruments V11.50, TianMin Products Science and Technology Development Co., LTD, Shenzhen, Guangdong, China) that were installed on the ceiling of the poultry house. The observations of the animal's behaviorial patterns were based on the scientific concept of animal behavioral traits from the UK Farm Animal Welfare Council (FAWC, 1995).
As a way of measuring the time and frequency of specific behaviors shown by the birds and evaluating their appearances, 10 min scan sampling was used per treatment group and a "deep skin harmful score" was obtained for each group. The animal's walking ability (gait score) (Kestin et al., 1992; Thomas et al., 2004), the presence of hock burns , drinking frequency, feather condition, and the presence of foot pad lesions were all measured using a three-point scale (1 represented normal, 2 represented mild, 3 represented severe) (Estevez et al., 2003; Škrbić et al., 2009; Zhu et al., 2012; Chen et al., 2015).

\subsection{Statistical analysis}

Data from this study- the main factors being heat stress and stocking density - were analyzed using a two-way ANOVA in SPSS (Statistical Package for Social Sciences; SPSS Inc., Chicago, IL, USA). Statistical significance was determined using a Duncan's multiple range test at a confidence level of $95 \%(P<0.05)$ (SPSS, 2010).

\section{Results}

Lipid profiles and levels of glucose, ALT, and AST are shown in Table 1. The concentrations of blood TAG, TC, LDL-C, AST, and ALT were found to be higher in the HS groups compared with the CON group $(P<0.05)$ : they were the highest in HSD group, but similar between the LSD and MSD groups. In contrast, the concentrations of HDL-C and glucose were lower in the HSD group compared to the other groups $(P<0.05)$. The glucose concentration was also lower in the MSD group compared with the CON group. AST and ALT concentrations were higher in the HS groups compared with the CON group $(P<0.05)$; concentrations of AST and ALT were higher in the HSD group than in the LSD or MSD groups $(P<0.05)$, but were not different between LSD and MSD.

Red blood cell (RBC) and platelet (PLT) profiles are shown in Table 2. The concentrations of blood HCT, RBC, MCV, MCH, MCHC, RDW, HGB, PLT, PCT, and MPV were lower in the HS groups compared with the CON group, with HSD showing the lowest levels of these factors $(P<0.05)$; however, the levels were similar between the LSD and MSD groups.

Concentrations of blood electrolytes are shown in Table 3. These values were higher in the HS groups compared with the CON group, with HSD displaying the highest levels $(P<0.05)$; however, the levels were similar between LSD and MSD.

Results of the blood $\mathrm{pH}$ values and gas concentrations are summarized in Table 4. Blood $\mathrm{pH}$ values were higher in the HS groups compared with the CON $\operatorname{group}(P<0.05)$, but were similar between the LSD and MSD groups. Furthermore, the concentrations of blood $p \mathrm{CO}_{2}, \mathrm{HCO}_{3}$, and $\mathrm{TCO}_{2}$ were higher in the $\mathrm{HS}$ groups compared with the $\mathrm{CON}$ 
Table 1. Effect of different stocking densities on the blood lipid profiles and levels of glucose, AST, and ALT in meat ducks exposed to heat stress.

\begin{tabular}{|c|c|c|c|c|}
\hline \multirow[b]{2}{*}{ Items $^{1}$} & \multicolumn{4}{|c|}{ Treatment groups } \\
\hline & $\mathrm{CON}$ & LSD & MSD & HSD \\
\hline $\mathrm{TC}\left(\mathrm{mg} \mathrm{dL}^{-1}\right)$ & $250.1 \pm 6.35^{2, c}$ & $314.8 \pm 7.51^{2, b}$ & $316.5 \pm 2.54^{b}$ & $348.9 \pm 1.85^{\mathrm{a}}$ \\
\hline HDL-C $\left(\mathrm{mg} \mathrm{dL}^{-1}\right)$ & $81.07 \pm 2.11^{\mathrm{a}}$ & $76.07 \pm 1.30^{\mathrm{a}}$ & $80.50 \pm 0.99^{\mathrm{a}}$ & $53.51 \pm 1.64^{b}$ \\
\hline TAG $\left(\mathrm{mg} \mathrm{dL}^{-1}\right)$ & $167.5 \pm 3.27^{\mathrm{c}}$ & $185.9 \pm 2.70^{b}$ & $187.2 \pm 3.42^{b}$ & $205.9 \pm 2.83^{\mathrm{a}}$ \\
\hline LDL-C $\left(\mathrm{mg} \mathrm{dL}^{-1}\right)$ & $155.3^{\mathrm{b}} \pm 3.54^{\mathrm{c}}$ & $179.6 \pm 2.24^{\mathrm{b}}$ & $176.5 \pm 2.20^{\mathrm{b}}$ & $206.0 \pm 3.46^{\mathrm{a}}$ \\
\hline Glucose $\left(\mathrm{mg} \mathrm{dL}^{-1}\right)$ & $186.0 \pm 3.55^{\mathrm{a}}$ & $166.0 \pm 3.20^{\mathrm{a}}$ & $151.1 \pm 2.05^{\mathrm{b}}$ & $153.0 \pm 2.03^{b}$ \\
\hline AST $\left(\mathrm{IUL}^{-1}\right)$ & $52.05 \pm 4.13^{\mathrm{c}}$ & $61.22 \pm 1.35^{\mathrm{b}}$ & $60.99 \pm 1.08^{\mathrm{b}}$ & $75.71 \pm 1.42^{\mathrm{a}}$ \\
\hline ALT $\left(\mathrm{IU} \mathrm{L}^{-1}\right)$ & $50.17 \pm 2.01^{\mathrm{c}}$ & $56.56 \pm 0.73^{b}$ & $55.59 \pm 1.07^{\mathrm{b}}$ & $66.04 \pm 1.28^{\mathrm{a}}$ \\
\hline
\end{tabular}

${ }^{1}$ TC represents total cholesterol, HDL-C represents high-density lipoprotein cholesterol, TAG represents triacylglycerol, LDL-C represents low-density lipoprotein cholesterol, AST represents aspartate aminotransferase, and ALT represents alanine transferase. ${ }^{2}$ Mean values \pm standard errors $(n=15) .{ }^{\text {a,b,c }}$ represent significant differences among the treatment groups at a confidence level of $95 \%(P<0.05)$.

Table 2. Effect of different stocking densities on red blood cell and platelet profiles of meat ducks exposed to heat stress.

\begin{tabular}{|c|c|c|c|c|}
\hline \multirow[b]{2}{*}{ Items $^{1}$} & \multicolumn{4}{|c|}{ Treatment groups } \\
\hline & $\mathrm{CON}$ & LSD & MSD & HSD \\
\hline \multicolumn{5}{|l|}{$\mathrm{RBC}$} \\
\hline $\operatorname{HCT}(\%)$ & $37.52 \pm 0.91^{2, a}$ & $34.62 \pm 0.78^{b}$ & $33.22 \pm 0.62^{b}$ & $30.59 \pm 0.41^{\mathrm{c}}$ \\
\hline $\operatorname{RBC}\left({\left.\mathrm{M} \mu \mathrm{L}^{-1}\right)}^{-1}\right.$ & $4.83 \pm 0.23^{\mathrm{a}}$ & $2.30 \pm 0.02^{\mathrm{b}}$ & $2.31 \pm 0.07^{\mathrm{b}}$ & $1.93 \pm 0.07^{\mathrm{c}}$ \\
\hline $\operatorname{MCV}(\mathrm{fL})$ & $152.3 \pm 1.65^{\mathrm{a}}$ & $145.6 \pm 1.73^{\mathrm{b}}$ & $142.8 \pm 1.65^{\mathrm{b}}$ & $139.6 \pm 0.88^{\mathrm{c}}$ \\
\hline $\mathrm{MCH}(\mathrm{pg})$ & $50.13 \pm 0.64^{\mathrm{a}}$ & $46.23 \pm 1.88^{\mathrm{b}}$ & $46.37 \pm 0.64^{\mathrm{b}}$ & $39.22 \pm 0.47^{\mathrm{c}}$ \\
\hline $\operatorname{MCHC}\left(\mathrm{g} \mathrm{dL}^{-1}\right)$ & $35.43 \pm 0.23^{\mathrm{a}}$ & $31.57 \pm 0.38^{\mathrm{b}}$ & $32.57 \pm 0.12^{\mathrm{b}}$ & $29.18 \pm 0.49^{c}$ \\
\hline RDW (\%) & $8.12 \pm 0.35^{\mathrm{a}}$ & $7.60 \pm 0.25^{\mathrm{b}}$ & $7.07 \pm 0.15^{\mathrm{b}}$ & $4.64 \pm 0.38^{\mathrm{c}}$ \\
\hline $\operatorname{HGB}\left(\mathrm{g} \mathrm{dL}^{-1}\right)$ & $13.38 \pm 0.28^{\mathrm{a}}$ & $11.32 \pm 0.33^{\mathrm{b}}$ & $10.70 \pm 0.17^{\mathrm{b}}$ & $9.22 \pm 0.39^{c}$ \\
\hline \multicolumn{5}{|l|}{ Platelets } \\
\hline $\operatorname{PLT}\left(\mathrm{K}_{\mu \mathrm{L}^{-1}}\right)$ & $0.41 \pm 0.05^{\mathrm{a}}$ & $0.27 \pm 0.03^{\mathrm{b}}$ & $0.26 \pm 0.04^{b}$ & $0.11 \pm 0.02^{c}$ \\
\hline PCT $(\%)$ & $0.50 \pm 0.02^{\mathrm{a}}$ & $0.36 \pm 0.08^{\mathrm{b}}$ & $0.26 \pm 0.04^{b}$ & $0.12 \pm 0.03^{\mathrm{c}}$ \\
\hline MPV (fL) & $8.58 \pm 0.17^{\mathrm{a}}$ & $7.52 \pm 0.41^{\mathrm{b}}$ & $6.83 \pm 0.20^{\mathrm{b}}$ & $3.81 \pm 0.15^{\mathrm{c}}$ \\
\hline
\end{tabular}

\footnotetext{
${ }^{1} \mathrm{HCT}$ represents hematocrit, RBC represents red blood cell, MCV represents mean corpuscular volume, MCH represents mean corpuscular hemoglobin, $\mathrm{MCHC}$ represents mean corpuscular hemoglobin concentration, RDW represents red blood cell distribution width, HGB represents hemoglobin, PLT represents platelet count, PCT represents plateletcrit, and MPV represents mean plasma volume. ${ }^{2}$ Mean values \pm standard errors $(n=15)$ $\mathrm{a}, \mathrm{b}, \mathrm{c}$ represent significant differences among treatment groups at a confidence level of $95 \%(P<0.05)$.
}

group $(P<0.05)$. They were also higher in HSD than in LSD or MSD $(P<0.05)$. However, they were found to be similar between LSD and MSD. Conversely, concentrations of $p \mathrm{O}_{2}$ were higher in the CON group compared with the HS groups $(P<0.05)$, but were similar between the LSD and MSD groups.

Blood IgG and corticosterone concentrations are shown in Table 5. The concentrations of blood IgG and corticosterone were significantly higher in the HS groups $(P<0.05)$ compared with the CON group. They were also significantly higher in HSD $(P<0.05)$ than in LSD or MSD, but they were similar between LSD and MSD.
Scores of animal behavioral traits under HS are shown in Table 6. Damage scores regarding the walking ability (gait), drinking frequency, presence of foot pad dermatitis, presence of hock burns, and feather condition of the HS groups were significantly higher $(P<0.05)$ than those of the CON group. They were also significantly higher $(P<0.05)$ in the HSD group than in the LSD or MSD groups. However, they were similar between LSD and MSD except for the fact that the drinking score was higher in MSD than in LSD. 
Table 3. Effect of different stocking densities on blood electrolytes $\left(\mathrm{mmol} \mathrm{L}^{-1}\right)$ in meat ducks exposed to heat stress.

\begin{tabular}{lrrrr}
\hline & \multicolumn{4}{c}{ Treatment groups } \\
\cline { 2 - 5 } Items & CON & LSD & MSD & HSD \\
\hline Sodium $\left(\mathrm{Na}^{+}\right)$ & $136.7 \pm 0.51^{*, \mathrm{c}}$ & $152.3 \pm 0.33^{\mathrm{a}}$ & $151.6 \pm 0.72^{\mathrm{a}}$ & $147.6 \pm 1.22^{\mathrm{b}}$ \\
Potassium $\left(\mathrm{K}^{+}\right)$ & $3.15 \pm 0.23^{\mathrm{c}}$ & $4.58 \pm 0.11^{\mathrm{a}}$ & $4.64 \pm 0.14^{\mathrm{a}}$ & $4.10 \pm 0.06^{\mathrm{b}}$ \\
Chloride $\left(\mathrm{Cl}^{-}\right)$ & $132.7 \pm 1.03^{\mathrm{c}}$ & $113.7 \pm 1.76^{\mathrm{a}}$ & $114.7 \pm 1.20^{\mathrm{a}}$ & $106.7 \pm 1.75^{\mathrm{b}}$ \\
\hline
\end{tabular}

* Mean values \pm standard errors $(n=15) .{ }^{\mathrm{a}, \mathrm{b}, \mathrm{c}}$ represent significant differences among treatment groups at a confidence level of $95 \%(P<0.05)$.

Table 4. Effect of different stocking densities on the blood $\mathrm{pH}$ and gas concentrations of meat ducks exposed to heat stress.

\begin{tabular}{|c|c|c|c|c|}
\hline \multirow[b]{2}{*}{ Items $^{1}$} & \multicolumn{4}{|c|}{ Treatment groups } \\
\hline & $\mathrm{CON}$ & LSD & MSD & HSD \\
\hline $\mathrm{pH}$ & $7.08 \pm 0.07^{2, c}$ & $7.35 \pm 0.06^{\mathrm{b}}$ & $7.37 \pm 0.02^{b}$ & $7.46 \pm 0.01^{\mathrm{a}}$ \\
\hline$p \mathrm{CO}_{2}(\mathrm{mmHg})$ & $32.83 \pm 2.07^{\mathrm{c}}$ & $45.32 \pm 1.20^{\mathrm{a}}$ & $44.57 \pm 0.64^{\mathrm{a}}$ & $39.30 \pm 0.25^{\mathrm{b}}$ \\
\hline $\mathrm{PO}_{2}\left(\mathrm{mmol} \mathrm{L}^{-1}\right)$ & $55.10 \pm 1.29^{\mathrm{a}}$ & $47.10 \pm 0.94^{b}$ & $46.24 \pm 0.59^{b}$ & $41.58 \pm 0.82^{\mathrm{c}}$ \\
\hline BEecf & $-3.15 \pm 0.09$ & $-3.04 \pm 0.09$ & $-2.82 \pm 0.14$ & $-3.16 \pm 0.45$ \\
\hline $\mathrm{HCO}_{3}\left(\mathrm{mmol} \mathrm{L}^{-1}\right)$ & $18.13 \pm 0.71^{\mathrm{c}}$ & $24.56 \pm 0.62^{\mathrm{a}}$ & $24.61 \pm 0.68^{\mathrm{a}}$ & $22.46 \pm 0.23^{b}$ \\
\hline $\mathrm{TCO}_{2}\left(\mathrm{mmol} \mathrm{L}^{-1}\right)$ & $19.75 \pm 0.77^{\mathrm{c}}$ & $26.86 \pm 0.61^{\mathrm{a}}$ & $26.70 \pm 0.77^{\mathrm{a}}$ & $24.38 \pm 0.49^{b}$ \\
\hline
\end{tabular}

\footnotetext{
${ }^{1} \mathrm{pH}$ represents the hydrogen exponent, $p \mathrm{CO}_{2}$ represents the partial pressure of carbon dioxide, $\mathrm{PO}_{2}$ represents the partial pressure of oxygen, BEecf represents the base excess in the extracellular fluid, $\mathrm{HCO}_{3}$ represents bicarbonate, $T \mathrm{CO}_{2}$ represents total carbon dioxide. ${ }^{2}$ Mean values \pm standard errors $(n=15){ }^{\mathrm{a}}, \mathrm{b}, \mathrm{c}$ represent significant differences among treatment groups at a confidence level of $95 \%(P<0.05)$
}

\section{Discussion}

The findings of this study are similar to prior literature which shows that the serum levels of ALT, AST, glucose, TC, TAG, and LDL-C in broiler chickens exposed to high ambient temperature are higher, while HDL-C levels are higher in the thermoneutral zone group (chickens reared at constant room temperature) (Chand et al., 2018). Furthermore, other reports show that the levels of blood TC, LDL-C, and AST in broiler chickens in a high-temperature environment are higher, while the levels of AG, HDL-C, glucose, and ALT are lower than those found in the control group (Bueno et al., 2017). The body of an animal can respond to stressors to maintain homeostasis; however, when homeostasis is disturbed by HS and HSD animals will try to develop a response mechanism involving physiological and behavioral adjustments to adapt themselves to the disturbance (Bueno et al., 2017). AST levels in the HSD group under HS were significantly increased. This could potentially lead to hepatic or muscular disorder and serious liver damage (Abudabos et al., 2013; Capitelli and Crosta, 2013).

Some studies have reported that ducks exposed to HS and HSD have lower levels of certain hematological parameters compared to control ducks due to the damage to red blood cells, the reduction in the output of red cells, or the decrease in the number and size of red blood cells (Bueno et al., 2017; Park and Park, 2017). Under normal environmental condi- tions, a decrease of red blood cells and haemoglobin levels in humans or animals can cause iron-deficiency anemia. Ducks under HS and HSD suffer from hemodilution due to increased water absorption even though there is no change in plasma volume. This can lead to the evaporation of water from cells, and can, in turn, lower the number of red blood cells and the haemoglobin level (Turkyilmaz, 2008; Park and Kim, 2017).

The sodium-potassium ATP pump is critical for maintaining the metabolism of biomass energy and the balance of water in the cell. The concentrations or densities of sodium, potassium, and chloride in the blood of poultry and buffalo cattle are known to be reduced due to HS (Kumar et al., 2010). Under HS and HSD conditions, panting by poultry can increase the loss of potassium via fecal urine, and this disruption the blood electrolyte balance can potentially lower productivity (Borges et al., 2004; Park and Park, 2017). When birds are exposed to HS and HSD, their body temperatures increase. In addition, as previously stated, hemodilution occurs and potassium is emitted in excess; thus, the concentration of potassium in the blood is decreased. The decrease of the blood chloride level in birds exposed to HS and HSD means that more chlorides are needed to accelerate oxidization in body fluids in order to normalize the blood $\mathrm{pH}$, which is rapidly escalated by blood alkalosis (Park and Kim, 2016; Park and Park, 2017). 
Table 5. Effect of different stocking densities on blood $\mathrm{IgG}$ and corticosterone levels $\left(\mathrm{ng} \mathrm{mL}^{-1}\right)$ in meat ducks exposed to heat stress.

\begin{tabular}{lrrrr}
\hline & \multicolumn{4}{c}{ Treatment groups } \\
\cline { 2 - 5 } Items & CON & LSD & MSD & HSD \\
\hline IgG & $187.5 \pm 4.01^{\mathrm{c}}$ & $299.6 \pm 5.63^{*, \mathrm{a}}$ & $307.7 \pm 3.38^{\mathrm{a}}$ & $250.0 \pm 3.03^{\mathrm{b}}$ \\
Corticosterone & $28.71 \pm 3.01^{\mathrm{c}}$ & $61.33 \pm 1.87^{\mathrm{b}}$ & $62.96 \pm 2.55^{\mathrm{b}}$ & $91.42 \pm 1.95^{\mathrm{a}}$ \\
\hline
\end{tabular}

* Mean values \pm standard errors $(n=15)$. ${ }^{\mathrm{a}, \mathrm{b}, \mathrm{c}}$ represent significant differences among treatment groups at a confidence level of $95 \%(P<0.05)$.

Table 6. Effect of stocking densities on the walking ability (gait), drinking frequency, presence of hock burn, presence of foot pad lesions, and feather condition scores in meat ducks exposed to heat stress.

\begin{tabular}{lrrrr}
\hline & \multicolumn{4}{c}{ Treatment groups } \\
\cline { 2 - 5 } Behavioral traits & CON & LSD & MSD & HSD \\
\hline Walking ability (gait) & $1.00 \pm 0.07^{*, \mathrm{c}}$ & $1.38 \pm 0.06^{\mathrm{b}}$ & $1.84 \pm 0.02^{\mathrm{b}}$ & $2.92 \pm 0.08^{\mathrm{a}}$ \\
Hock burns & $1.00 \pm 0.08^{\mathrm{c}}$ & $1.15 \pm 0.04^{\mathrm{b}}$ & $1.86 \pm 0.05^{\mathrm{b}}$ & $2.78 \pm 0.09^{\mathrm{a}}$ \\
Foot pad lesions & $1.00 \pm 0.05^{\mathrm{c}}$ & $1.17 \pm 0.07^{\mathrm{b}}$ & $1.75 \pm 0.04^{\mathrm{b}}$ & $2.82 \pm 0.05^{\mathrm{a}}$ \\
Feather condition & $1.00 \pm 0.16^{\mathrm{c}}$ & $1.55 \pm 0.03^{\mathrm{b}}$ & $1.76 \pm 0.08^{\mathrm{b}}$ & $2.58 \pm 0.07^{\mathrm{a}}$ \\
Drinking & $1.00 \pm 0.18^{\mathrm{d}}$ & $1.37 \pm 0.04^{\mathrm{c}}$ & $2.07 \pm 0.07^{\mathrm{b}}$ & $3.00 \pm 0.09^{\mathrm{a}}$ \\
\hline
\end{tabular}

* Mean values \pm standard errors $(n=24)$. ${ }^{\mathrm{a}, \mathrm{b}, \mathrm{c}, \mathrm{d}}$ represent significant differences among treatment groups at a confidence level of $95 \%(P<0.05)$.

Our results have shown that HSD rearing increases the blood $\mathrm{pH}$ values of meat ducks exposed to $\mathrm{HS}$ in addition to lowering their blood gas concentrations; this could eventually induce blood alkalosis, which is known to cause problems in the central nervous systems of bird (Borges et al., 2007; Park and Park, 2017). Birds kept under HS and HSD conditions will try to lower blood $p \mathrm{CO}_{2}$ to bring their body temperatures down. This is done by removing $\mathrm{CO}_{2}$ from their lungs via panting (Mahmoudnia and Madani, 2012; Park and Kim, 2017).

Under stress, birds show higher concentrations of corticosterone while concentrations of their immunity substances are found to be lower than the control group (Fraisse and Cockrem, 2006). HSD rearing of meat ducks exposed to HS also causes reduced serum immune protein and IgG concentrations, while concentrations of corticosterone, a stress hormone, are increased, which leads to increased mortality.

This study assumes that the HSD rearing of meat ducks during summertime will stress the poultry and affect their behavior. The gait score is a subjective evaluation of the animal's walking ability caused by the ducks' physical inactivity due to the shortage of space when stocking densities are increased (Škrbić et al., 2009). An inverse correlation between the stocking density and drinking frequency per duck was observed in this study. This research also found that the number of times that ducks in HSD group drank was notably lower compared with animals in the LSD or MSD group. Animals that drink more water under HS and HSD rearing conditions show natural drinking and water-associated activities, such as straining and preening their plumage with water, which are considered to be behavioral requirements that satisfy "healthy" animal behavioral traits (Heyn et al., 2006). In meat ducks exposed to HS, the need to drink increases as the stocking density is increased. When litter becomes dirty or the lying resting time of animals is increased, the frequency of the occurrence of hock burns and foot pad dermatitis is increased. In the event of high-density rearing, hock burns, also known as ammonia burns, occur due to a combination of moisture and the high ammonia content in the litter (Berg, 2004). Hock burns and foot pad dermatitis are closely related to one another, and litter quality is critical factor controlling the occurrence of such health issues (Dawkins et al., 2004; Kiaer et al., 2006). Under HS and HSD rearing conditions, ducks show poor quality feathers, which can lead to different skin lesions (Škrbić et al., 2009). The negatively affected behavioral traits of ducks under HS and HSD conditions also make it difficult for them to take in the diet provided, which results in a decrease in body weight gain and an increase in mortality due to poor nutritional metabolism and unbalanced blood homeostasis.

\section{Conclusions}

The findings of this study show that when meat ducks are exposed to heat stress in combination with high stocking density conditions, the blood homeostasis of the poultry is decreased due to environmental stress which lowers red blood cell and platelet profiles, blood electrolytes, blood gas, and $\operatorname{IgG}$ concentrations but increases concentrations of ALT, 
AST, $\mathrm{pH}$, and corticosterone. Rearing meat ducks at a stocking density of three to four birds per square meter $\left(\mathrm{m}^{2}\right)$ during summer was found have an obvious influence on blood homeostasis and the behavioral traits of the animals, putting them in a dangerous position.

Data availability. The data sets are available upon request from the corresponding author.

Author contributions. BSP, SOP and VAZ designed and performed the experiments, derived the models and analyzed the data. SOP and KHU wrote the paper with input from all authors.

Competing interests. The authors declare that they have no conflict of interest.

Acknowledgements. This research was supported by Ministry of Agriculture, Food and Rural Affairs (project number C101061301-03), Republic of Korea.

Edited by: Manfred Mielenz

Reviewed by: Elif Babacanoglu and one anonymous referee

\section{References}

Abudabos, A. M., Samara, E. M., Hussein, E. O. S., Al-Ghadi, M. Q., and Al-Atiyat, R. M.: on the performance and welfare of broiler chickens, Ital. J. Anim. Sci., 12, 66-71, 2013.

Aengwanich, W.: Effects of high environmental temperature on blood indices of thai indigenous chickens, thai indigenous chickens crossbred and broilers, Int. J. Poult. Sci., 6, 427-430, 2007.

Alaeldein, M., Abudabos, M. E., Samara, O. S., Elsayeid, Hussein, Q., Mu'ath, A., Ghadi, M., and Raed, A. A.: Impacts of stocking density on the performance and welfare of broiler chickens, Italian. J. Anim. Sci., 12, 66-71, 2013.

Altan, Ö., Altan, A., Cabuk, M., and Bayraktar, H.: Effects of heat stress on some blood parameters in broilers, Turk. J. Vet. Anim. Sci., 24, 145-148, 2000.

An, Y. S., Park, J. G., Jang, I. S., Sohn S. H., and Moon, Y. S.: Effects of high stocking density on the expressions of stress and lipid metabolism associated genes in the liver of chicken, J. Life Sci., 22, 1672-1679, 2012.

Babacanoglu, E., Yalcin, S., and Uysal, S.: Evaluation of a stress model induced by dietary corticosterone supplementation in broiler breeders: effects on egg yolk corticosterone concentration and biochemical blood parameters, Brit. Poult. Sci., 54, 677-685, 2013.

Bang, H. T.: Effect of different feeding times using a diet containing betaine on production, blood profile and a short chain fatty acid in meat ducks exposed to a scorching heat wave, Kor. J. Oil Chem., 32, 427-438, 2015.

Berg, C.: Pododermatitis and hock burn in broiler chickens, in: Measuring and auditing broiler welfare, edited by: Weeks, C. A. and Butterworth, A., CABI Publishing, Wallingford, UK, 37 pp., 2004.

Borges, S. A., Silva, A. V. F. D., Ariki, J., Hooge D. M., and Cummings, K. R.: Dietary electrolyte balance for broiler chickens exposed to thermoneutral or heat-stress environments, Poult. Sci., 82, 428-435, 2003.

Borges, S. A., Majorka, A., Hooge, D. M., and Cummingst, K. R.: Physiological responses of broiler chickens to heat stress and dietary electrolyte balance(sodium plus potassium minus chloride, milliequivalents per kilogram, Poult. Sci., 83, 1551-1558, 2004.

Borges, S. A., Silva, A. V. F. D., and Maiorka, A.: Acid-base balance in broilers, World's Poult. Sci. J., 63, 73-81, 2007.

Bueno, J. P. R., Nascimento, M. R. B. de M., Martins, J. M. da S., Marchini, C. F. P., Gotardo, L. R. M., Sousa, G. M. R. de., Mundim, A. V., Guimarães, E. C., and Rinaldi, F. P.: Effect of age and cyclical heat stress on the serum biochemical profile of broiler chickens, Semina: Ciências Agrárias, Londrina, 38, 1383-1392, 2017.

Capitelli, R. and Crosta, L.: Overview of psittacine blood analysis and comparative retrospective study of clinical diagnosis, hematology and blood chemistry in selected psittacine species, Veter, Clin, North America: Exotic Anim. Practice, Texas, 16, 71-120, 2013.

Chen, Y., Aorigele, C., Yan, F., Li, Y., Cheng, P., and Qi, Z.: Effect of production system on welfare traits, growth performance and meat quality of ducks, South Afr. J. Anim. Sci., 45, 173-179, 2015.

Chand, N., Naz, S., Rehman, Z., and Khan, R. U.: Blood biochemical profile of four fast-growing broiler strains under high ambient temperature, Appl. Biol. Chem., 61, 273-279, 2018.

Close, B., Banister, K., Baumans, V., Bernoth, E. M., Bromage, N., Bunyan, J., Erhardt, W., Flecknell, P., Gregory, N., Hackbarth, H., Morton D., and Warwick, C.: Recommendations for euthanasia of experimental animals, Part 2. Lab. Anim., 31, 1-32, 1997.

Daramola, J. O., Abioja, M. O., and Onagbesan, O. M.: Heat stress impact on livestock production, in: Environmental Stress and Amelioration in Livestock Production, edited by: Sejian, V., Naqvi, S., Ezeji, T., Lakritz, J., and Lal, R., Springer, Berlin, Heidelberg, 3, 53-73, 2012.

Dawkins, M. S., Donnelly, C. A., and Jones, T. A.: Chicken welfare is influenced more by housing conditions than by stocking density, Nature, 427, 342-344, 2004.

Estevez, I., Keeling, L. J., and Newberry, R. C.: Decreasing aggression with increasing group size in young domestic fowl, Appl Anim. Behav. Sci., 84, 213-218, 2003.

Etches, R. J., John T. M., and Gibbins, A. M. V.: Behavioural, physiological, neuroendocrine and molecular responses to heat stress, in: Poultry production in hot climates, edited by: Daghir, N. J., Trowbridge, Cromwell press, 49-80, 2008.

FAWC: Report on the welfare of turkeys, Farm Animal WelFare Council, Surrey 1, 1995.

Fraisse, F. and Cockrem, J. F.: Corticosterone and fear brhaviour in white and brown caged laying hens, Br. Poult. Sci., 47, 110-119, 2006.

Habibu, E., Ikira, N. M., Buhari, H. U., Aluwong, T., Kawu, M. U., Yaqub, L. S., Tauheed, M., and Isa, H. I.: Effect of molasses supplementation on live weight gain, haematologic parameters and erythrocyte osmotic fragility of broiler chickens in the hotdry season, Inter. J. Vet. Sci., 3, 181-188, 2014. 
Heyn, E., Damme, K., Manz, M., Remy, F., and Erhard, M. H.: Adequate water supply for pekin ducks: alternatives for bathing, Deut. Tierarztl. Woch., 113, 90-93, 2006.

HSUS: An HSUS report: The welfare of animals in the duck industry, HSUS Report 23, The Humane Society of the United States, 2008.

Kestin, S. C., Knowles, T. G., Tinch, A. E., and Gregory, N. G.: Prevalence of leg weakness in broiler chickens and relationship with genotype, Vet. Rec., 131, 190-194, 1992.

Kjaer, J. B., Su, G., Nielsen, B. L., and Sørensen, P.: Foot pad dermatitis and hock burn in broiler chickens and degree of inheritance, Poult. Sci., 85, 1342-1348, 2006.

Kumar, B. V. S., Singh, G., and Meur, S. K.: Effects of addition of electrolyte and ascorbic acid in feed during heat stress in buffaloes, Asian-Aust, J. Anim. Sci., 23, 880-888, 2010.

Mahmoudnia, N. and Madani, Y.: Effect of betaine on performance and carcass composition of broiler chicken in warm weather - A review, Int. J. Agri. Sci., 2, 675-691, 2012.

Mello, J. L. M., Boiago, M. M., Giampietro-Ganeco, A., Berton, V., Vieira, L. D. C., Souza, R. A. I., Ferrari, F. B. I., and Borba, H.: Periods of heat stress during the growing affects negatively the performance and carcass yield of broilers, Arch. Zootec., 64, 339-345, 2015.

Na, J. C., Hwangboa, J., Kim, J. H., Kang, H. G., Kim, M. J., Kim, D. W., Choi, H. C., and Hong, E. C.: Performance and carcass ratio of large-type female broiler at different stocking densities, Kor. J. Poult. Sci., 39, 305-313, 2012.

Park, B. S. and Park, S. O.: Effects of feeding time with betaine diet on growth performance, blood markers, and short chain fatty acids in meat ducks exposed to heat stress, Livestock Sci., 199, 31-36, 2017.
Park, S. O. and Kim, W. K.: Effects of betaine on biological functions in meat-type ducks exposed to heat stress, Poult. Sci., 96, 1212-1218, 2016.

Scot PIL training manual: Care and handling of laboratory animals, Glasgow University, UK, 1994.

Škrbić, Z., Pavlovski, Z., Lukić, M., Perić, L., and Milošević, N.: The effect of stocking density on Certain broiler welfare parameters, Biotech. Anim. Husband., 25, 11-21, 2009.

Slimen, B., Najar, T., Ghram, A., and Abdrrabba, M.: Heat stress effects on livestock: molecular, cellular and metabolic aspects, a review, J. Anim. Physiol. Anim. Nutr., 100, 401-412, 2016.

SPSS: Statistical Package for Social Sciences for Window (version 19.0), Chicago, IL, SPSS Inc., 2010.

Thomas,D. G., Ravindran, V., Thomas, D. V., Camden, B. J., Cottam, Y. H., Morel,P. C. H., and Cook, C. J.: Influence of stocking density on the performance, carcass characteristics and selected welfare indicators of broiler chickens, New Zealand Veter. J., 52, 76-81, 2004.

Turkyilmaz, M. K.: Effect of stocking density on stress reaction in broiler chickens during summer, Turk. J. Vet. Anim. Sci., 32, $31-$ 36,2008

Xie, M., Jiang, Y., Tang, J., Wen, Z. G., Huang, W., and Hou, S. S.: Effects of stocking density on growth performance, carcass traits, and foot pad lesions of White Pekin ducks, Poult. Sci., 93, 1644-1648, 2014.

Yu, D. J., Na, J. C., Jang, B. G., Lee, D. S., Kim, S. H., Kim, J. H., K. Kang, K. H., Suh O. S., and Kang, H. S.: Effect of stocking density on performance and blood characteristics of broiler in summer, Kor. J. Poult. Sci., 34, 105-110, 2007.

Zhu, Y. W., Xie, M., Huang, W., Yang, L., and Hou, S. S.: Effects of biotin on growth performance and foot pad dermatitis of starter White Pekin ducklings, Br. Poult. Sci., 53, 646-650, 2012. 